\title{
Characteristics of HIV Infected Patients with Biopsy Diagnosed Spongiotic Dermatitis*
}

\author{
Gus W. Krucke ${ }^{1}$, Benjamin L. Cooper ${ }^{1}$, Deanna E. Grimes ${ }^{2}$, Richard M. Grimes ${ }^{1 \#}$ \\ ${ }^{1}$ Department of Medicine, Medical School, University of Texas Health Science Center at Houston, Houston, USA; ${ }^{2}$ Department of \\ Nursing Systems, School of Nursing, University of Texas Health Science Center at Houston, Houston, USA. \\ E-mail: " richard.m.grimes@uth.tmc.edu
}

Received August 11 ${ }^{\text {th }}, 2011$; revised September $14^{\text {th }}$, 2011; accepted October $5^{\text {th }}, 2011$.

\begin{abstract}
Purpose: Twenty-six HIV patients with biopsy diagnosed spongiotic dermatitis (SD) were studied to determine their demographic and clinical characteristics. The condition was also investigated to determine if it was linked to the immune reconstitution inflammatory syndrome (IRIS). Methods: All patients whose skin biopsies were diagnosed by a pathologist as $S D$ were identified. Medical records were reviewed to extract demographic descriptors, viral loads and CD4+ counts at the time that SD occurred. In an attempt to determine if the condition could be linked to Immune Reconstitution Syndrome (IRIS), the time from nadir CD4+ count to the occurrence of SD was determined. Results: SD patients were found to be older than expected but were similar to other clinic patients with regard to race/ethnicity and gender. CD4+ counts, viral loads were not related to SD. SD did not seem to be related to IRIS because few cases occurred within the time frame associated with IRIS. SD frequently appeared on the limbs although the literature suggests a more frequent appearance on the trunk and buttocks. Discussion: HIV clinicians may expect to see SD on occasion and it may appear in unusual body sites and at any time during the course of the infection.
\end{abstract}

Keywords: Spongiotic Dermatitis, HIV Infection, Immune Reconstitution Inflammatory Syndrome

\section{Introduction}

Spongiotic dermatitis (SD), an intensely pruritic dermatologic condition, is diagnosed by biopsy [1]. Lesions of this condition are typically found on the trunk or buttocks but may appear on any part of the body. Early lesions are erythematic and, with time, may darken to black. In the absence of effective treatment, the skin may become rough, ooze and crust and constant scratching may lead to scarring. The etiology of SD is not fully understood but SD has been linked to contact dermatitis, food and drug allergies, and reactions to insect bites, suggesting an immune reaction [2]. SD also has been linked to infectious conditions such as hepatitis C infection [3] and HTLV-1 infection [4]. A variant of SD is has been found in patients with heavily pigmented skin [5]. Investigators have noted high levels of proliferative activity of CD8 (+) T cells in patho-

\footnotetext{
*This study was supported by the Baylor-UT Houston Center for AIDS Research (CFAR), a National Institutes of Health-funded program (AI036211).

*The authors have no conflicts of interest with regard to this manuscript. This study was approved by the Committee for the Protection of Human Subjects at the University of Texas (The institutional review board).
}

logic examination of tissue samples [6]. Immunocompromised patients are prone to the above risk factors for SD and often suffer from multiple dermatological conditions which may require a skin biopsy in order to make a diagnosis [7]. So, one would expect that a linkage would have been made between SD and HIV infection. However, this has not been the case. No references to SD in HIV patients could be found in the general medical literature or in review articles of dermatologic conditions in HIV infected persons [8-11].

Because of the lack of literature describing SD in the HIV infected population and because skin lesions have been found to occur as part of the immune reconstitution syndrome (IRIS), [12] the authors report on a group of HIV patients diagnosed with SD. Specifically, we describe the patient's age, nadir CD4+ count, time since initiation of antiretroviral therapy and viral load, all characteristics that might be associated with IRIS.

\section{Methods}

This study was conducted at the Thomas Street Health Center of the Harris County Hospital District in Houston, 
Texas. This clinic has over 5000 active patients. The clinic maintains a minor emergency and treatment room with the capacity to collect skin samples for subsequent examination by a pathologist.

The investigators reviewed the biopsy reports of 161 skin specimens that had been collected at the clinic between 2005 and 2009. Twenty six of these specimens were classified as spongiotic dermatitis by a pathologist. The electronic medical record was examined for each patient with this diagnosis. Demographic data were extracted from the record. In an attempt to determine if the condition could be linked to Immune Reconstitution Syndrome (IRIS), CD4+ t lymphocyte data were also collected. IRIS is described as occurring within 60 - 90 days after a patient's CD4+ count begins to rise following initiation of antiretroviral therapy (ART) [12,13]. Therefore, the patient's nadir CD4+ count was collected and the date that the assay was done. The date that the skin biopsy was performed was also recorded and the CD4+ count closest to the date of the biopsy was also recorded. If spongiotic dermatitis was associated with IRIS, it should have occurred shortly after the nadir CD4+ count. Therefore the time from the nadir to the biopsy was calculated. The increase of the CD4+ count between the nadir and the time of SD was also recorded because IRIS has been linked to rapid and large increases in CD4+ counts [13]. The location of the lesion was also recorded to determine if SD in HIV infected persons' lesions followed the usual pattern of SD being found on the trunk and buttocks.

\section{Results}

Twenty six patients had been diagnosed with SD at the time of this investigation. Eighteen or $70 \%$ of the diagnosed SD patients were African-American while the remaining eight were evenly split between White and Hispanic. Twenty $(77 \%)$ of the subjects were male and six (23\%) were female. These demographics are similar to the clinic's population. Approximately $20 \%$ of the patient population at the clinic, however, is less than 30 years of age while all of the patients diagnosed with SD were 30 years of age or greater. As can be seen from Table 1, the CD4+ counts nearest to the time of the occurrence of SD exhibited a wide range of CD4+ counts from 31 to 1226 . Similarly, the viral load at the time that SD occurred ranged $<400$ to $>750,000$ copies of HIV viral RNA. All of the CD4+ counts and viral loads were performed within two months of the skin biopsy. Also, a broad range of nadir CD4+ counts was represented in the SD patients with a range from as low as 5 cells to as high as 389. When the time from the nadir CD4+ count until the occurrence of SD was examined, the range of times was from 8 months before the nadir to 76 months after its
Table 1. Immunological characteristics of HIV-infected patients with spongiatic dermatitis $(\mathrm{N}=\mathbf{2 6})$.

\begin{tabular}{|c|c|c|}
\hline $\begin{array}{c}\text { Clinical } \\
\text { Character Istics }\end{array}$ & Number & Percentage \\
\hline \multicolumn{3}{|c|}{ CD 4 Count at time of SD } \\
\hline$<100$ & 10 & $38 \%$ \\
\hline $101-200$ & 2 & $8 \%$ \\
\hline $200-500$ & 5 & $19 \%$ \\
\hline$>500$ & 9 & $35 \%$ \\
\hline \multicolumn{3}{|l|}{ Nadir CD 4 Count } \\
\hline$<50$ & 13 & $50 \%$ \\
\hline $50-99$ & 2 & $8 \%$ \\
\hline $100-199$ & 6 & $23 \%$ \\
\hline $200-500$ & 5 & $19 \%$ \\
\hline \multicolumn{3}{|c|}{ Viral Load at Time of SD } \\
\hline$<400$ & 14 & $54 \%$ \\
\hline $401-10,000$ & 3 & $11 \%$ \\
\hline $10,001-100,000$ & 3 & $11 \%$ \\
\hline$>100,001-500,000$ & 2 & $8 \%$ \\
\hline$>500,000$ & 4 & $15 \%$ \\
\hline \multicolumn{3}{|c|}{$\begin{array}{l}\text { Increase In CD } 4 \text { Count from } \\
\text { NADIR to SD Diagnosis }\end{array}$} \\
\hline$<50$ & 10 & $38 \%$ \\
\hline $51-100$ & 2 & $8 \%$ \\
\hline $101-200$ & 2 & $8 \%$ \\
\hline $201-500$ & 7 & $27 \%$ \\
\hline$>500$ & 5 & $19 \%$ \\
\hline \multicolumn{3}{|c|}{$\begin{array}{c}\text { Time from Nadir to SD } \\
\text { Diagnosis }\end{array}$} \\
\hline SD before Nadir & 1 & $4 \%$ \\
\hline$<1$ Months & 4 & $15 \%$ \\
\hline 1 Month - 1 Year & 4 & $15 \%$ \\
\hline 1 - 3 Years & 7 & $27 \%$ \\
\hline $3+$ Years & 10 & $38 \%$ \\
\hline \multicolumn{3}{|l|}{ Location of the lesion } \\
\hline Trunk & 2 & $8 \%$ \\
\hline Head and neck & 3 & $12 \%$ \\
\hline Upper extremity & 10 & $38 \%$ \\
\hline Lower extremity & 10 & $38 \%$ \\
\hline Unknown & 1 & $4 \%$ \\
\hline
\end{tabular}


occurrence. The lesions tended to be located on the arms and legs and only five patients had lesions that were located on the trunk or the head and neck.

\section{Discussion}

This is the first paper that describes SD in HIV infected persons. It seems that the lesion is not related to the immunological state of these patients nor does the level of virus seem to be factor in its occurrence. Attempts to relate SD to the time frame that is associated with IRIS were not successful. Of note, SD in these HIV-infected patients tended to be located on the extremities, not on the trunk and buttocks as in non-HIV infected persons. So, those who are treating HIV infected persons may expect to see SD on occasion and it may appear in unusual body sites and at any time during the course of the infection.

\section{REFERENCES}

[1] K. Gupta, “Deciphering Spongiotic Dermatitides,” Indian Journal of Dermatology Venereolology and Leprology, Vol. 74, No. 5, 2008, pp. 523-526. doi:10.4103/0378-6323.44332

[2] M. Jeffries, “What Is Spongiotic Dermatitis?” 2010. http://ezinearticles.com/?What-Is-Spongiotic-Dermatitis? \&id=1068322

[3] Gruppo Italiano Studi Epidemiologici in Dermatologia (GISED), "Lichen Planus and Liver Diseases: A Multicentre Case-Control Study,” British Medical Journal, Vol. 300, No. 6719, 1990, pp. 227-230. doi:10.1136/bmj.300.6719.227

[4] R. R. Bonamigo, K. Borges, J. Rietjens, S. Arenzon, L. P. Blanco and R. Loureiro, "Human T lymphotropic Virus 1 and Hepatitis C Virus as Risk Factors for Inflammatory Dermatoses in HIV-Positive Patients,” International Journal of Dermatology, Vol. 43, No. 8, 2004, pp. 568570. doi:10.1111/j.1365-4632.2004.02179.x

[5] B. T. Summey, S. E. Bowen and H. B. Allen, "Lichen Planus-Like Atopic Dermatitis: Expanding the Differen- tial Diagnosis of Spongiotic Dermatitis,” Journal of $\mathrm{Cu}$ taneous Pathology, Vol. 35, No. 3, 2008, pp. 311-314. doi:10.1111/j.1600-0560.2007.00806.X

[6] M. Deguchi, H. Ohtani, E. Sato, Y. Naito, H. Nagura, S. Aiba and H. Tagami, "Proliferative Activity of CD8(+) T Cells as an Important Clue to Analyze T Cell-Mediated Inflammatory Dermatoses," Archives Dermatology Research, Vol. 293, No. 9, 2001, pp. 442-447. doi:10.1007/s004030100255

[7] M. M. Khambaty, "Dermatology of the Patient with HIV," Emergency Medicine Clinics of North America, Vol. 28, No. 2, 2010, pp. 355-368. doi:10.1016/j.emc.2010.01.001

[8] P. K. Ramdial, "Dermatopathological Challenges in the Human Immunodeficiency Virus and Acquired Immunodeficiency Syndrome Era,” Histopathology, Vol. 56, No. 1, 2010, pp. 39-56. doi:10.1111/j.1365-2559.2009.03456.x

[9] G. E. Rodwell and T. G. Berger, "Pruritus and Cutaneous Inflammatory Conditions in HIV Disease," Clinics in Dermatology, Vol. 18, No. 4, 2000, pp. 479-484. doi:10.1016/S0738-081X(99)00143-1

[10] D. Rigopoulos, V. Paparizos and A. Katsambas, "Cutaneous Markers of HIV Infection,” Clinics in Dermatology, Vol. 22, No. 6, 2004, pp. 487-498. doi:10.1016/j.clindermatol.2004.07.007

[11] J. Luther and M. J. Glesby, "Dermatologic Adverse Effects of Antiretroviral Therapy," American Journal of Clinical Dermatology, Vol. 8, No. 6, 2007, pp. 221-233. doi:10.2165/00128071-200708040-00004

[12] S. Mori and P. Levin, “A Brief Review of Potential Mechanisms of Immune Reconstitution Inflammatory Syndrome in HIV Following Antiretroviral Therapy,” International Journal of STD \& AIDS, Vol. 20, No. 7, 2009, pp. 447-452. doi:10.1258/ijsa.2009.008521

[13] S. A. Shelburne, F. Visnegarwala, J. Darcourt, E. A. Graviss, T. P. Giordano, A. C. White Jr. and R. J. Hamill, "Incidence and Risk Factors for Immune Reconstitution inflammatory Syndrome during Highly Active Antiretroviral Therapy,” AIDS, Vol. 19, No. 4, 2005, pp. 399-406. doi:10.1097/01.aids.0000161769.06158.8a 